\title{
Meeting the needs of pediatric nurse practitioner students today: Challenges of implementing a new curriculum
}

\author{
Tami L. Thomas *1,2, Imelda Reyes ${ }^{2}$, Jeannie Rodriguez ${ }^{2}$, Erin Hernandez ${ }^{2}$ \\ ${ }^{1}$ Florida International University, Nicole Wertheim College of Nursing and Health Sciences Miami, Fl, Unites States \\ ${ }^{2}$ Emory University, Nell Hodgson Woodruff School of Nursing, Atlanta, Ga, United States
}

Received: August 15, 2015

DOI: $10.5430 /$ jnep.v6n1p39
Accepted: September 21, $2015 \quad$ Online Published: October 13, 2015

URL: http://dx.doi.org/10.5430/jnep.v6n1p39

\begin{abstract}
There has been a dramatic increase of nursing students who have completed schooling in the more generalized field of family practice, and yet, workforce data still shows a growing need for nurse practitioners specializing in pediatrics. In an era of diminishing resources, pediatric programs have always struggled, especially with the alignment of pedagogy and technology. But in the fall of 2012, a team comprised of clinical and tenure-earning faculty rose to overcome these challenges to achieve satisfaction for both teachers and students. Now, after two years of successfully using innovative strategies and improving the quality of our approaches as well as our brand, feedback from our team, faculty, and students remains high. Below we detail our endeavor of encouraging the expansion of Pediatric Nurse Practitioner programs, our evaluation processes, and the educational practices intended to inspire faculty.
\end{abstract}

Key Words: Education, Nursing practice, Pediatrics, Graduate students

\section{INTRODUCTION}

The need to keep an updated nurse practitioner (NP) curriculum that ensures competence and knowledge has been a constant and ever-changing issue as far back as 1965 when Dr. Loretta Ford and Dr. Henry Silver began the nurse practitioner movement to meet their community's pediatric care needs. ${ }^{[1]}$ While teaching the newer generations the medical art of caring for children is anything but novel, a problem arises when there are not enough caregivers to treat those in need of care. A general shortage of primary care providers is well documented within the United States. ${ }^{[2]}$ In the past ten years alone, the subjects of availability and training for specialized care providers, especially regarding the primary and acute care children of vulnerable populations, has be- come a major issue. ${ }^{[3]}$ When the AAP released their 2013 policy statement regarding the pediatric workforce, they too highlighted that there are not enough pediatric providers to give care to children in both underserved and rural areas. ${ }^{[4]}$ With children being a stable part of the population, it is of the greatest importance to meet their needs by finding and teaching providers to specialize in the areas of pediatric expertise.

\section{IMPORTANCE OF THE PEDIATRIC- FOCUSED EDUCATION}

It was recently noted that while the number of Pediatric Nurse Practitioner (PNP) graduates has remained stable at 800 per year, the graduate rates from family nurse practitioner (FNP)

\footnotetext{
*Correspondence: Tami L. Thomas; Email: tthomas@ fiu.edu; Address: Nicole Werthiem College of Nursing and Health Sciences, Miami, FL, Unites States.
}

Published by Sciedu Press 
programs has doubled from 3,000 per year in 2004 to 6,000 in 2011. ${ }^{[5]}$ When it came to FNP patient profiles, Freed et al. (2010) observed that children, the majority of whom were ten years of age or older, only made up a small percentage of those who received care. ${ }^{[6]}$ With these kinds of statistics, an alarming question is raised: if the curriculums of FNP and adult NP students don't fully address the needs of the pediatric patient, are there enough advanced practice nurses out there with a strong pediatric knowledge base?

In an effort to address this problem as well as ongoing issues faced by PNP educators - program flexibility, program length, engaging new and different generations of learners ${ }^{[7]}$ - it was suggested that nursing academics focus on pediatric education, including the quantity and quality of the clinical experience, the duration of the program, and funding. ${ }^{[5]}$ Given that we are teaching the future pediatric providers that are in need, it is imperative that we structure the student's learning environment in a way that best meets their needs and most efficiently prepares them for the workforce.

\section{MeEting THE NEEDS}

As nursing educators, we are constantly working to conquer the needs of our students and the conditions of our governing organizations as efficiently as possible. During the more than three-decade existence of our institution's PNP program, which includes a primary care tract and the ten year-old acute care tract (see Table 1), an outstandingly high proportion of students have passed the certification exams; yet, despite these successes, exit interviews have shown graduates expressing trepidation about their role as an independent care provider. To encompass these concerns as well as the changes made to the NP core competencies in 2012 by the National Organization of Nurse Practitioner Faculties (NONPF), ${ }^{[8]}$ curricular changes were implemented in the fall of 2012 so that student need and NONPF requirements coincided with one another. In this manuscript, the best practices and challenge responses experienced by our PNP program following these changes, specifically from 2012 to 2014, are shared.

Table 1. Old curriculum

\begin{tabular}{|c|c|}
\hline $\begin{array}{ll}\text { - } & \text { Core MSN Requir } \\
\text { - } & \text { Health Policy and Finance for Advanced Prac } \\
\text { - } & \text { Theory and Research Applications (3) } \\
\text { - } & \text { Spanish for Healthcare Professionals (2) } \\
\text { - } & \text { Advanced Pharmacology (3) } \\
\text { - } & \text { Advanced Pathophysiology (3) } \\
\text { - } & \text { Genetics and Embryology APRN (3) }\end{array}$ & $\begin{array}{l}\text { I for Primary and Acute PNP (credit hour) } \\
\text { e Nursing ( } 3 \text { ) } \\
\text { Leadership Issues (3) }\end{array}$ \\
\hline $\begin{array}{l}\text { Primary Care Specific } \\
\text { - } \quad \text { PNP I: Advanced Health Assessment and } \\
\text { - } \quad \text { Primary Care of Children (5) } \\
\quad \text { Illnesses (6) } \\
\text { - } \quad \text { PNP III: Management of Children with Acute } \\
\text { Chronic Illnesses/Synthesis (7) } \\
\text { - } \quad \text { Seminar in Pediatric Acute Care (2) }\end{array}$ & $\begin{array}{l}\text { Acute Care Specific } \\
\text { - } \quad \text { PNP I: Advanced Health Assessment and Primary Care of Children (5) } \\
\text { - } \quad \text { PNP Acute Care I: Developmental Approaches (1) } \\
\text { - } \quad \text { PNP Acute Care II: Management of Children with Acute and Critical } \\
\text { Care Problems I (7) } \\
\text { - } \quad \text { PNP Acute Care III: Management of Children with Acute and Critical } \\
\text { - Care Problems II (7) } \\
\text { - } \quad \text { PNP Acute Care IV: Residency (5) } \\
\text { - } \quad \text { Cultural Competence for Advanced Practice Nurses (2) } \\
\text { 760 Clinical Hours Completed }\end{array}$ \\
\hline
\end{tabular}

Note. Clinical hours captured in classes in italics.

\section{TEAMING UP FOR CHANGE}

To facilitate change and enhance our program, the PNP faculty decided the best first step would be to create a better sense of solidarity between teachers and students. Since there seemed to be no evidence of this kind of all-inclusive departmental identity outside of the business world, reorganizing the PNP program in this vein demanded fresh perspectives on team work and curriculum revision. The concept coalesced well, with academic acceptance given by administration, faculty, and students alike.

For the graduate PNP program, a specialized orientation was offered to students so that they would have the opportunity to become familiar with PNP faculty and learn more about the school's resources. The orientation included an innovative daylong program, which took place before the start of classes, comprised of a networking luncheon, distribution of 
student/faculty "Team Peds" jackets, a cohort photo, and an afternoon social event for PNP alumni and their families.

To further bolster our concept of unanimity, we have utilized the Blackboard site to foster collaborations between students and faculty that have included professional presentations, manuscripts, research projects, and leadership opportunities within professional organizations, not to mention encouraging a network of support for individuals across independent endeavors. Team Peds has organized their efforts around the principles of Commission on Collegiate Nursing Education's (CCNE) Standards for Accreditation. ${ }^{[9]}$ Now, as changes to curriculum occur, the core pediatric faculty works together as a team to address challenges and changes as they occur.

\section{THE NEW MSN CURRICULUM}

When considering the concepts defined by Giddens et al. that have to be addressed so that NP programs might meet future workforce needs, ${ }^{[10]}$ national leaders and our clinical partners alike encouraged focusing on having standardized preclinical preparation, standardized students assessments, and immersive clinical experiences. Gerard et al. also highlighted the need for nurse practitioners to be well versed in measurement of outcomes, health promotion principles, and financially minded health care professionals. ${ }^{[11]}$ With these aims in mind, a new curricular redesign began for PNP graduate students in 2013 (see Table 2).

Table 2. New curriculum

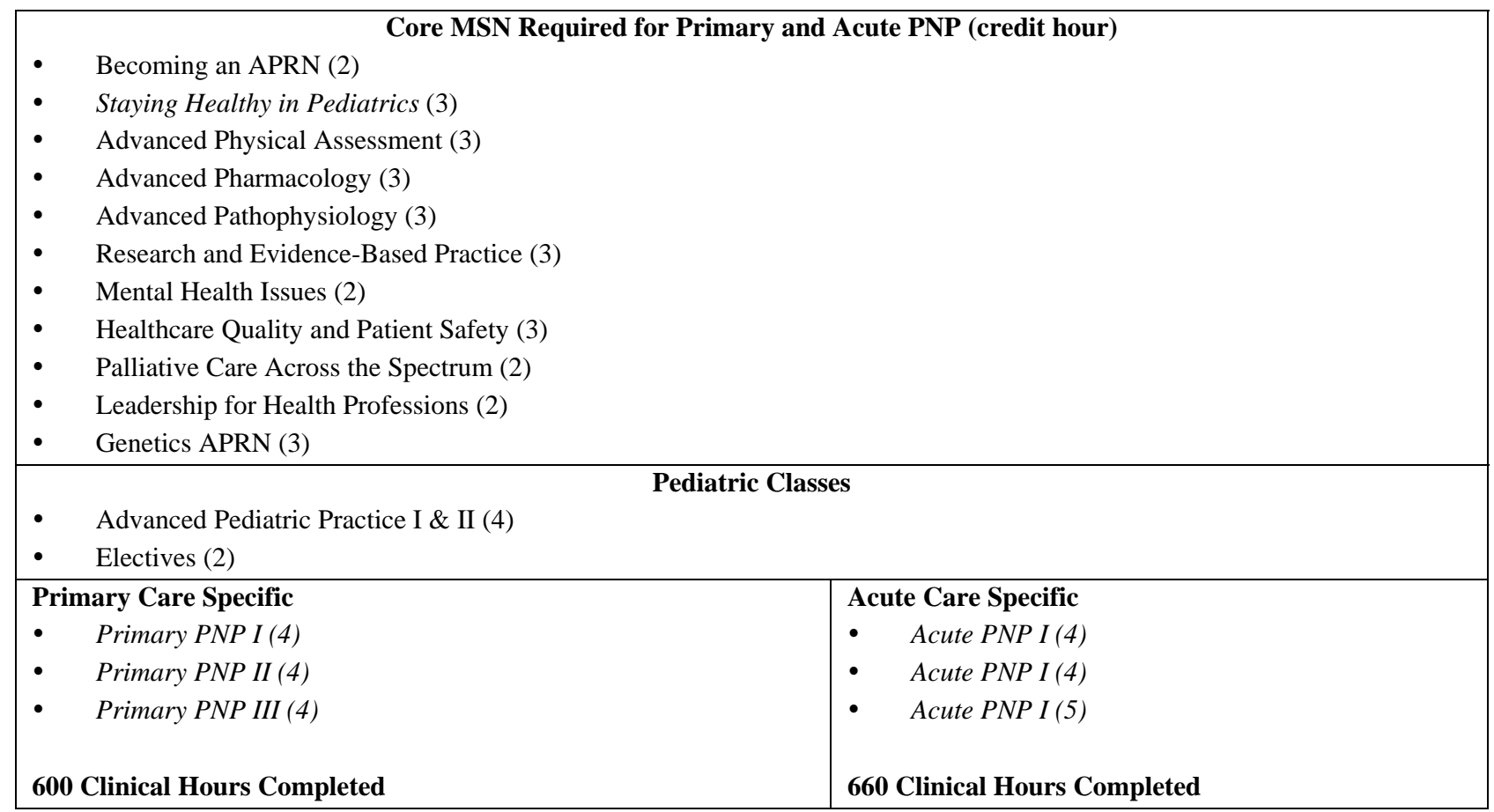

Note. Clinical hours captured in classes in italics.

With this redesign, all of the NP programs would share the 3 P's of NP education: advanced Physical assessment, advanced Pathophysiology, and advanced Pharmacology. Other areas of the core competencies, such as quality of care, patient safety, promotion of optimal wellness, palliative care, mental health care, and other advanced practice issues were likewise introduced into the new curriculum. Schedules and teaching methods were also adjusted for the redesign. An alternating of a four-week block of didactic content with a four-week block of dedicated clinical time was used so that students would be able to absorb and practice the knowledge gained before enacting them in a clinical setting. Hybrid courses, which implement face-to-face and online methodologies such as VoiceThread and discussion boards, were intended to give greater flexibility while incorporating online learning principles.

Taught entirely from the lifespan perspective, our new curriculum introduced five new courses. The first, Staying Healthy in Pediatrics (cross listed with Optimal Wellness), was offered as a joint venture with Optimal Wellness in the first semester, teaching students about promoting optimal wellness for their patients and families along with incorporating optimal wellness for themselves. The second, Becoming an Advanced Practice Registered Nurse (APRN), introduced 
students to the professional responsibilities of the APRN and health policy issues that guide their practice. The other three classes included Mental Health, Palliative Care, and Quality/Patient Safety, all of which were topics that had been interwoven into other classes but not given dedicated time. So that respective student groups could experience discussions solely concerning their specialties, pediatric clinical courses also included breakout seminars discussing areas such as primary care and acute care (see Figure 1). The addition of these courses provided a strong message to the students about the importance of health promotion for patients, families, and themselves; the need to have a thorough understanding of the NP role; and the growing and vital needs in the US to address mental health and end of life issues.

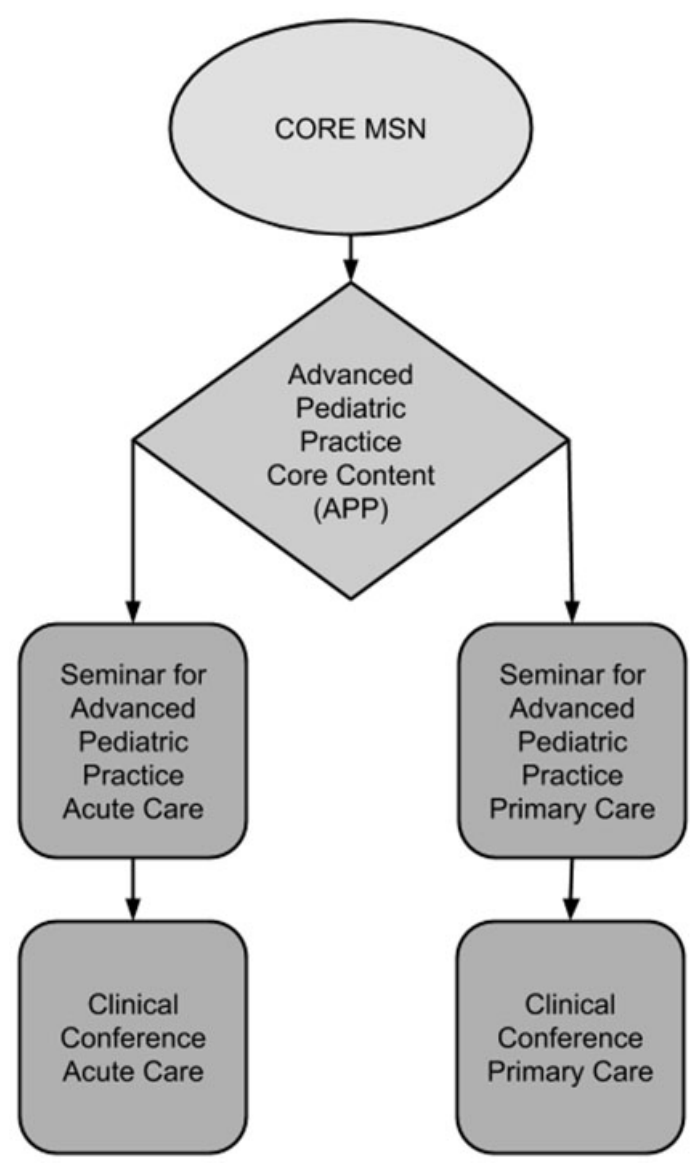

Figure 1. Vision for new curriculum

The curriculum's new design has been beneficial in a lot of ways, including gaining efficiencies from the faculty workload perspective by having students enroll in core classes together and the seamlessly delivered and reinforced content (see Figure 1). For example, pediatric students enrolled in pharmacology can engage in a module on antimicrobials and may feel that content is not relevant to their population. As an unfolding exemplar, in advanced pediatric practice class we discuss pediatric specific conditions and, when needed, pull pharmacological principles from their core class, e.g., which antibiotics are best suited for pneumonia for children under and/or over the age of five. We reinforce the need to determine the selection of pharmacologic interventions based on relevant etiologies. Then, we further divide their clinical conference where other considerations are discussed such as delivering care for a child being treated in an outpatient setting or a hospitalized child with pneumonia.

\section{PNP-SPECIFIC CURRICULAR CHANGES}

In the original curriculum, a student enrolling with a BSN in nursing could complete the primary care program of study in three full time semesters and the acute care program of study in four full time semesters; core MSN classes were taken with the full nurse practitioner cohort and included advanced pathophysiology, advanced pharmacology, health policy, and ethics. Specialty-specific classes for the pediatric primary and acute care students were bundled into both didactic and clinical content for larger credit hour classes; credit for clinical experiences were captured in these classes. While this curriculum offered the advantage of having several smaller and intimate pediatric-focused courses, the students voiced that they never felt like they were part of the larger MSN nurse practitioner student body. When they were grouped into larger core science classes, a theme of dissatisfaction arose amongst student evaluations; issues cited included a lack of pediatric focus and redundancy of pediatric-specific content. From a larger non-PNP faculty perspective, courses such as advanced health assessment were being offered in two distinct formats, one course for the pediatric nurse practitioner students in a Pediatric Health Assessment course and one course for the rest of the nurse practitioner cohort. With the three pillars of NP education, health assessment was the only class that pediatric students were receiving without a lifespan perspective.

In accordance with the MSN changes, we elevated the curriculum of the PNP student to focus on a lifespan perspective as to cover the years from infancy through young adulthood, and even onto college age. Recent discussions on the role of PNPs to offer care through transitional periods such as young adulthood, as evidenced by the National Association of Pediatric Nurse Practitioner (NAPNP) Position Statement on Age Parameters, illustrate that the newer classes offered the opportunity for students to explore these and other clinical issues from a pediatric-specific lens that extends into the young adult years. ${ }^{[12]}$ 


\section{Challenges}

A global challenge that all programs face is the overwhelming amount of content needed to ensure that our students achieve the competencies as outlined by our professional bodies. ${ }^{[13]}$ The Primary Care PNP program encountered multiple obstacles, including the extension of the program of study by one semester, the student/faculty concern about the fragmentation of pediatric content among varying classes, the increased amount of content that had to be delivered during block scheduling, and changes to an online format for a few classes.

The content doubled because of the compressed time period and the class block schedule required students to meet nearly every day for class. From a clinical placement perspective, some preceptors have expressed that having students five days a week was a struggle and students faced challenges well when they were fully prepared.

\section{RAPID CYCle CHANGe TO MEET THE CHALLENGES}

Identifying the areas in need of improvement and developing new strategies for delivering content and providing effective clinical experiences has become an essential element of our program. As such, we took our quality improvement plans very seriously as to be able to address all of our most pertinent challenges and create an optimized program for all those involved. These plans, discussed at least twice a semester during PNP faculty meetings, addressed issues such as faculty concerns, process/content mapping, development of standard operating procedures, and transparency among the leadership team. We incorporated many forms of quality appraisal from our students as well to help support our improvement plans including course evaluations, informal feedback, clinical logs, weekly minute papers, and reflection papers. The community atmosphere developed with our Team Peds concept was very helpful in gathering the personal evaluations of faculty and students.

To address the issue of the lack of pediatric focus in courses including the entire NP cohort, faculty requested that they be involved in the courses in a coordinator/co-coordinator capacity and/or to be consulted regarding course content. For the course on health assessment, for example, pediatric students are grouped with PNP faculty members to ensure that time is taken to frame and practice didactic course content with a pediatric-specific lens. In the mental health course, pediatric attend lecture with the entire NP cohort and then attend a separate seminar given by PNP faculty with the appropriate field experience. For other core courses that did not include breakout labs or seminars such as pharmacology, courses like pediatric pharmacotherapeutics were implemented.

To verify that we are working well with our mentors and preceptors, we also carefully monitor the virtual clinical schedules and experiences. The comfort level with online technology for both faculty and students is understandably varied, so faculty seminars and huddle-type sessions were held concerning the designing of tests, student pilot courses, and the new technology in general that included more specific topics such as Adobe Connect live sessions, live information links in resource guides, online video-style modules, and Google solutions to deploy objective structured clinical exams (OSCE). Tools used through OSCE stations are crafted to capture the clinical reasoning skills of the student by asking them to answer questions based on presented clinical scenarios such as being asked to interpret the spirometry results of an asthma patient after the administration of albuterol. Students expressed that they liked the new type of assessment in lieu of the traditional multiple-choice questionnaire.

\section{Conclusion}

Providing those in need with enough Primary Care Providers is a challenge that will continue on forever and offering the appropriate curriculum content is the base of this perpetual issue. ${ }^{[14]}$ And as the role of the pediatric nurse practitioner continues to encompass more challenging competencies and is further refined, the needs of current students have to be constantly reassessed and updated. While we experienced our own set of challenges putting our new curriculum in place, the use of rapid change cycles, consideration of student evaluations, the implementation of new ideas, and collaborations with interprofessional colleagues helped lead to success as well as student/faculty satisfaction. Results like these have increased our resolve and have inspired the attitude that though change is difficult, adhering to a good rapid cycle change plan will bring about flexibility and creativity. Curricular changes remain fluid as faculty continues to submit changes for future cohorts and the leadership team continues to support ongoing evidence-based changes.

\section{CONFLicts of InTEREST Disclosure}

The authors declare that there is no conflict of interest.

\section{REFERENCES}

[1] American Association of Colleges of Nursing (AACN). Standards for Accreditation of Baccalaureate and Graduate Nursing Programs.
2013. Available from: http://www.aacn.nche.edu/educatio n-resources/MastersEssentials11.pdf

[2] Bellack JP, Graber DR, O’Neil EH, et al. Curriculum trends in nurse 
practitioner programs: Current and ideal. Journal of Professional Nursing. 1999; 15(1): 15-27. http://dx.doi.org/10.1016/S87 55-7223 (99) 80021-0

[3] Basco WT, Rimsza ME, Hotaling AJ, et al. Pediatrician workforce policy statement. Pediatrics. 2013; 132(2): 390-397. PMid:23897908 http://dx.doi.org/10.1542/peds. 2013-1517

[4] Donelan K, DesRoches CM, Dittus RS, et al. Perspectives of physicians and nurse practitioners on primary care practice. New England Journal of Medicine. 2013; 368: 1898-1906. PMid:23675658 http://dx.doi.org/10.1056/NEJMsa1212938

[5] Martyn K, Martin J, Gutknecht SN. The Pediatric Nurse Practitioner Workforce: Meeting the Health Care Needs of Children. Journal of Pediatric Health Care. 2013; 27: 400-405. PMid:23631880 http://dx.doi.org/10.1016/j.pedhc.2013.03.005

[6] Melander S, Settles J. Introducing the new NONPF skills manual. Nurse Practitioner. 2011; 36: 14. PMid:22008595 http://dx.doi .org/10.1097/01.NPR.0000406493.92038.60

[7] Silver HK, Ford LC, Day LR. The pediatric nurse-practitioner program: expanding the role of the nurse to provide increased health care for children. JAMA. 1968; 204: 298-302. http://dx. doi.o $\mathrm{rg} / 10.1001 / \mathrm{jama} .1968 .03140170014003$

[8] Freed FL, Dunham KM, Lamarand K, et al. Family nurse practitioners: Roles and scope of practice in the care of pediatric patients. Pediatrics. 2010; 126: 861-864. PMid:20956411 http: //dx.doi.org/10.1542/peds.2010-2157
[9] Freed GL, Dunham KM, Loveland-Cherry CJ, et al. Pediatric nurse practitioners in the United States: current distribution and recent trends in training. The Journal of Pediatrics. 2010; 157(4): 589-593. e581. http://dx.doi.org/10.1016/j.pedhc. 2014.03.001

[10] Gerard SO, Kazer MW, Babington L, et al. Past, Present, and Future Trends of Master's Education in Nursing. Journal of Professional Nursing. 2014; 30: 326-332. PMid:25150418 http://dx.doi.org $/ 10.1016 / j$.profnurs. 2014.01 .005

[11] Giddens JF, Lauzon-Clabo L, Morton PG, et al. Re-envisioning Clinical Education for Nurse Practitioner Programs: Themes From a National Leaders' Dialogue. Journal of Professional Nursing. 2014; 30(3): 273-278. PMid:24939338 http://dx.doi.org/10.1016 /j.profnurs.2014.03.002

[12] Grumbach K, Hart LG, Mertz E, et al. Who is caring for the underserved? A comparison of primary care physicians and nonphysician clinicians in California and Washington. Annals of Family Medicine. 2013; 1: 97-104. http://dx.doi.org/10.1370/afm. 49

[13] Hittle K, Bolick B, Kline-Tilford A, et al. NAPNAP Position Statement on Age Parameters for Pediatric Nurse Practitioner Practice. Journal of Pediatric Health Care. 2014; 28: 15A-16A.

[14] Thomas TL, Imelda R, Amy B, et al. Technology and teaching: Avoiding the pitfalls, increasing student engagement, and improving outcomes. Journal of Nursing Education and Practice. 2015; 5(3): 33-38. http://dx.doi.org/10.5430/jnep.v5n3p33 